\title{
ALLOCATION OF RESOURCES FOR HOSPITAL EVACUATIONS VIA SIMULATION
}

\author{
Esengul Tayfur \\ Kevin Taaffe \\ 110 Freeman Hall \\ Department of Industrial Engineering, Clemson University \\ Clemson, SC 29634-0920, U.S.A.
}

\begin{abstract}
Department of Health and Environmental Control (DHEC) issued an order recently requiring that all hospitals have an evacuation plan with the following components: sheltering plan, transportation plan and staffing plan. Also, these hospitals carry out tests to become familiar with the sequence of events that need to occur for an effective evacuation. However, risk managers only have a limited number of scenarios that they can actually consider for testing, due to time constraints or complexity in performing the tests. They can not make sure of the efficiency and effectiveness of their plans. Inefficient and ineffective evacuation plan may result in tragic loss of life as occurred in evacuation of hospitals as a result of Hurricanes Katrina and Rita. This research proposes a simulation model that can be used by the hospitals to evaluate their performances in case of an evacuation due to a hurricane.
\end{abstract}

\section{INTRODUCTION}

Hospital operators do not prefer to shut down the hospitals as they play an important role in emergency response plan. However, it is not certain how the hospital perform in case it needs to evacuate. Although hospitals have evacuation plans, they need to deal with issues not mentioned in the evacuation plans.

Therefore, this research builds the representation of the hospital evacuation event due to hurricane via simulation. This model is built as general and flexible as possible in order to allow all risk managers to test evacuation plans by only entering some input data parameters. Currently, the model is finalized and verification, which takes so much time due to the complexity of the model, is being done. Later, this research will present the allocation of the resources with the objectives of minimizing cost or minimizing evacuation completion time within a pre-specified evacuation completion time via simulation-optimization approach. Also, this research will uncover the extent to which evacuation decisions made by hospital operators will affect the outcome of the overall evacuation.

\section{LITERATURE REVIEW}

Research in this area can be grouped in two main categories: (1) behavioral and social science, and (2) modeling and operations.

There exists extensive literature about behavioral and social science. Quarantelli (1980) can be considered as one of the first papers that directly addresses the development of a framework for human decision making. Later, Sorensen and Mileti (1987), Sorensen (1991), and de Silva et al. (2003) focused on the improvement of decision making procedures within general evacuations. Beside these, Frantzich (1997) analyzed the risk where hospitals serve as support for first responders. More directly related to this research is the work by Vogt $(1990,1991)$ and McGlown (1999). These researches specifically examine the decision-making process regarding evacuation of health care facilities and special needs populations. Each researcher offered a model for classifying variables that appear to be significant in influencing the evacuation vs. shelter-inplace decision, as well as the timing of such decisions. Specifically, Vogt and McGlown note how these variables are all factors in an individual's ability to cope with evacuation. The United States Government Accountability Office investigated the issues related to the health care facility evacuation due to hurricanes and released a summary report (GAO 2006).

The above references indicate significant contributions that address how a decision to evacuate takes place, and how responsive the general public will be to an imminent disaster or threat. However, these studies focus on human behavior/ response and decision making, and the objective was not to propose optimal transportation exit paths, timing of evacuation notices, or resource assignments.

In addition to these, there has been a wide range of researchers working under the extent of modeling and operations of this area. Most of the researchers have emphasized on general population as their focus was the use of roadway infrastructure to move people away from a hazard. Sheffi et al. (1982), Hobeika and Jamei (1985), Tufekci 


\section{Tayfur and Taaffe}

(1995), and Pidd et al. (1996) have used statistic analysis tools including macro/meso-simulation and network-based methods extensively so as to conduct evacuation research. Chen (2003) and Radwan et al. (2005) focused on the application of micro simulation and dynamic optimization under this area. Many of these researchers propose operational policies for mass evacuations. Tufekci (1995) suggests a methodology for allocation of evacuees to the shelters with the use of least congested roadways.

However, researches mentioned above focused on general public evacuation, not a special population such as hospital patients and staff. The authors has seen that the problem of developing robust evacuation plans using quantitative techniques is still largely unresearched. Taaffe et al. (2005) introduced the issues and complexities inherent in such a quantitative analysis. Afterwards, Taaffe and Tayfur (2006) built a deterministic optimization model to present the resource and schedule requirements in case of a hospital evacuation required due to a hurricane. Taaffe et al. (2006) proposed a preliminary simulation model and made initial analysis in order to understand, analyze, and improve hospital evacuation plans. Later, Tayfur and Taaffe (2007) developed this model a little further and made some analysis to allocate the resources while minimizing cost and to observe the effects of decision making during an evacuation.

As one of the major interest areas is investigating the effects of officials' decisions, articles related to traffic analysis are searched in order to find expected increase in travel times over time. There are several evacuation traffic models developed and currently available to support the planning and analysis of emergency evacuation. Chang (2003) analyzed these models and suggested how to improve the operational planning of emergency evacuation. Tanaka et al. (2006) investigated the traffic congestion and dispersion of vehicles during an evacuation and FEMA/Corps Hurricane Study Program (1986-2006) focused on the determination of the clearance times needed to conduct a safe and timely evacuation in case of a hurricane event.

\section{MODELING SYSTEM}

As mentioned earlier, Tayfur and Taaffe (2007) developed a preliminary simulation model and experimented some cases to find the allocation of resources for hospital evacuation due to hurricanes. That model was based on input obtained from risk managers and officials from several hospitals, which are Beaufort, Cape Canaveral, Georgetown, Greenville, Medical University of South Carolina, and Tampa.

Later, more input is obtained from those risk managers and officials in order to define the system more clearly. With this information, the way each process take place, the type of the resources used in each process, the priority se- quence of using a resource in a process, the duration of processes, and etc. are described in more detail.

Due to the level of randomness and considerably high number of procedure steps to follow in the system, some assumptions have to be made. In this paper, the boundaries of the system and the assumptions have been decided for the last time, and the preliminary simulation model (Tayfur and Taaffe 2007) is developed including all these assumptions and finalized.

\subsection{System Details}

The definition of this system and assumptions are made as general as possible and model is built as flexible as possible so that this model can be utilized by all hospitals with few input parameter changes.

Consider a hospital of which evacuation plan options are being evaluated. This hospital can send its patients, medical staff, and basic supporting equipment to finite number of sheltering facilities (hospitals) in a neighboring safe region. The sheltering facilities are assumed to have adequate advanced medical equipment and supplies to take care of the patients that are transferred from the hospital being evacuated. Thus, none of the advanced medical equipment and supplies is transferred from the evacuating hospital.

Patients are grouped into three categories. A Type 1 patient represents critical care patients, such as those either waiting for or in recovery from serious operation, or that have an extreme ailment. A Type 3 patient is denoted as any patient who is a candidate for early release and can expect to be released, based on any number of reasons where care can not be provided away from the hospital. All other patients would fall into a larger, middle group of patients occupying medical/surgical (or med/surge) beds. This group is denoted as Type 2 .

There exist three types of vehicles: buses, vans, and ambulances. The number of patients that can be transferred via each vehicle type is assumed, but the model is built in a very flexible way that these numbers can be modified in case the sizes of the vehicles change. The following statements explain the current assumptions related to the allocation of vehicles. An ambulance can transfer only one Type 1 patient at a time and can not transfer other types of patients unless all Type 1 patients are evacuated to the sheltering facilities. Also, a Type 1 patient can not be transferred via other vehicle types. On the other hand, Type 2/3 patients can be transferred with buses and vans. While transferring these types of patients, priority is given to the buses as a bus can transfer considerably double capacity of patients that a van can transfer. It is assumed that a bus can transfer 12/16 Type 2/3 patients while a van can transfer $6 / 8$ Type $2 / 3$ patients. Besides these, if all Type 1 patients are evacuated and all of the buses and vans are busy, then an ambulance can transfer $2 / 2$ Type $2 / 3$ patients. 


\section{Tayfur and Taaffe}

It is assumed that there are a finite number of physicians, which are not subjected to change due to the evacuation during hurricane. This is due the fact that the hospitals do not consider extreme conditions such as evacuations while hiring the physicians.

Nurses are categorized into three types: Critical care nurse (CCN), medical-surgical nurse (MSN), and medical staff (MS). Critical care nurses are the ones who have the highest knowledge and work in progressive care unit, intensive care unit and operating room, whereas the medicalsurgical nurses take care of the adult patients in many settings, such as inpatient care units, clinics, ambulatory care units, long-term care units, urgent care centers, surgical centers, etc. On the other hand, the remaining other professional nurses, who work in physical therapy, respiratory unit, or work without a license, are considered as medical staff. The allocation of a specific nurse depends on the nature of the process, the type of the patient s/he takes care of, and the priority sequence considered in that process. This is explained with more details in the next section. It is assumed that it takes TRIA $(2,3,4)$ minutes for a nurse to come to the required place after his/her allocation.

\subsection{Process Details}

In this section, processes during hospital evacuation are explained in sequence and more detail.

In this specific case, it is assumed that the announcement of a possible landfall is made 96 hours before its occurrence. Hospitals are assumed to start preparation process 24 hours after landfall announcement. During preparation process, the documents of each patient are gone through, and the patients are controlled to see their current conditions. As there is finite number of beds for each type of patient at each sheltering facility, the nurses in evacuating hospital contacts with the sheltering facilities in order to arrange the beds, to which patients can be transferred. Also, nurses contact with the families of Type 3 patients as they can all be released earlier than their expected release time. However, it is found out that approximately $25 \%$ of Type 3 patients can not be evacuated due to the fact that the relatives can not be reached or some of the relatives can not come to the hospital to pick up their patients. Therefore, $25 \%$ of Type 3 patients are assumed to need evacuation. The time distribution assumed for preparation process is TRIA $(10,20,30)$ minutes per patient. During this process, a CCN takes care of a Type 1 patient, while a MSN and MS takes care of Type 2/3 patients, respectively. After patients are gone through this process, Type 3 patients, whose relatives are able to look after them, are discharged from the hospital. Also, the sheltering facility each patient will be transferred to is assigned during this process. Later, patients continue to wait in their location for the hospital operators' order to evacuate.
After evacuation order is given, patients follow these steps: release their beds, go to staging area, stage onto a vehicle, transfer to sheltering facility via a vehicle, and vacate the vehicle. The assumed time distributions of each process for each type of patient are given in Table 1.

Table 1: Process Time Distributions

\begin{tabular}{|l|l|l|l|}
\hline \multirow{2}{*}{ Type } & \multicolumn{3}{|l|}{$\begin{array}{l}\text { Time distribution } \\
\text { (per patient-in terms of minutes) }\end{array}$} \\
\cline { 2 - 4 } & Release Bed & $\begin{array}{l}\text { Go to Staging } \\
\text { Area }\end{array}$ & $\begin{array}{l}\text { Stage onto } \\
\text { vehicle }\end{array}$ \\
\hline $\mathbf{1}$ & TRIA $(6,10,14)$ & $\operatorname{TRIA}(8,10,12)$ & $\operatorname{TRIA}(8,10,12)$ \\
\hline $\mathbf{2}$ & TRIA $(4,5,6)$ & $\operatorname{TRIA}(6,8,10)$ & $\operatorname{TRIA}(5,6,7)$ \\
\hline $\mathbf{3}$ & TRIA $(1,2,3)$ & $\operatorname{TRIA}(4,6,8)$ & $\operatorname{TRIA}(4,6,8)$ \\
\hline
\end{tabular}

The time distribution of unloading a patient from a vehicle process is same as the staging a patient onto a vehicle. Currently, the distances between the evacuating hospital and sheltering facilities are assumed to be same, 45 mile. The speed of vehicles is assumed to be 45 mile/hour. Thus, it takes about an hour to travel from evacuating hospital to a sheltering facility and vice versa.

If patient is Type 1 , then patient stays in his/her bed until an ambulance, a CCN, and another nurse with a priority sequence as MS, MSN, and $\mathrm{CCN}$, respectively, are available simultaneously. The reason for the priority sequence while allocating the second nurse type is based on the idea that there is already one $\mathrm{CCN}$ who has the enough knowledge to take care of that patient, the second nurse is only needed while moving the patient from bed to stretcher, from the room to the vehicle, and staging the patient onto the vehicle. The second nurse is released so as to be used by other processes after staging the patient onto the vehicle. If there is less than 6 hours left before the occurrence of landfall, each Type 1 patient stay in her/his bed with an accompanying CCN.

If a patient is Type 2 or 3 , then s/he will release her/his bed and go to the staging area so as to be staged onto a vehicle, bus or van, respectively. Note that each vehicle can only go to a specific sheltering facility. Therefore, patients are grouped and staged onto a vehicle according to the sheltering facility they are supposed to go. If there is not any vehicle available for staging a patient and there is enough capacity in staging area, then this patient can wait in the staging area until staging onto a vehicle becomes possible for this patient. It is assumed that finite number of patients (currently 50 Type $2 / 3$ patients in our model) can wait for a vehicle arrival or for being staged onto the vehicle in the staging area. If there is a case when a vehicle just returns from its trip to the sheltering facility and there are patients who have been waiting for a vehicle to come in the staging area and a patient, who just released her/his bed and came to the staging area, the priority for staging onto the vehicle is given to the first patient who have waited in 


\section{Tayfur and Taaffe}

the staging area. The last coming patient, who has not waited in the queue, starts waiting for the other patients to be staged onto the vehicle and continues to wait if the vehicle becomes full and there is no other available vehicle at that time.

A nurse accompanies to a Type $2 / 3$ patient while releasing her/his bed, going to the staging area and staging onto the vehicle. The priority sequence while allocating this nurse is MS and MSN respectively. After staging first patient on a vehicle or staging her/him to keep in the staging area, a check is done whether MSN is the type of this patients' nurse. If not and if there is an available MSN, then a MSN is allocated and the existing nurse is released after allocating MSN. If there is not available MSN at that time, then the existing nurse is not released and allocated to take care of the upcoming patients. The nurses of the upcoming patients are released after the patients are staged onto the vehicle. The existing nurse can take care of up to $6 / 8$ Type $2 / 3$ patients. When the last patient, who fills the capacity of nurse, is staged onto the vehicle, the nurse types are checked over again. There must be one MSN and one MS that get on the vehicle and assist to 6/8 Type 2/3 patients during their transfer to the sheltering facilities. If the staging nurse of the last patient and the first seized nurse for the vehicle satisfy this condition, then patients are transferred to the sheltering facilities. If not, then the required type of nurse is allocated and the staging nurse of the last patient in that group is released. If the vehicle is not full although all patients that are assigned to that sheltering facility are staged onto that vehicle, then the capacity of fullness is checked to decide on how many nurse to allocate. If the vehicle is less than half full, then only one MSN is seized. Again, if the first seized nurse of the vehicle is not MSN and the staging nurse of the last patient is MSN, then the first seized nurse of the vehicle is released. If the first seized nurse is MSN, then the staging nurse of the last patient is released immediately after staging her/his patient. Other than these cases, the staging nurse of the last patient is released after staging her/his patient and the first seized nurse is released after allocating a MSN.

The method of allocating nurses mentioned above is valid for vans. With the current assumption, buses have double capacity of a van. The logic in allocating nurses for bus is assumed to be the same way as allocating nurses for staging patients on two subsequent vans. Therefore, two MSN and two MS are allocated for a full bus.

If an ambulance is used to transfer Type $2 / 3$ patients, the staging nurses of the patients staged on ambulance are released and no other nurse is allocated.

On the other hand, a nurse is allocated for 6/8 Type $2 / 3$ patients, who wait for an available vehicle in the staging area. When the first patient staged in the group (6/8 Type $2 / 3$ patients, who starts waiting in the staging area), the staging nurse of this patient is checked whether $\mathrm{s} / \mathrm{he}$ is MSN. If $\mathrm{s} /$ he is MSN, then this nurse is continued to be al- located and the staging nurses of the upcoming patients are released. But, if s/he is not MSN and if there is a MSN available, then that MSN is allocated and the staging nurse of this patient is released. Also, the staging nurses of the upcoming patients are released after staging their patients in the staging area. If the staging nurse of the first patient staged in the group is MS and there is no available MSN, then this nurse is continued to be seized for this group and the staging nurses of the upcoming patients are released after staging them in the staging area. Every time this type of patient is staged on a vehicle, a control is done whether $\mathrm{s} / \mathrm{he}$ is the last one in that group. If yes, then the nurse seized for that group is released.

When there is less than 6 hours left before the occurrence of landfall, evacuation is stopped for Type 2/3 patients as it is stopped for Type 1 patients. Similarly, when there are still Type $2 / 3$ patients laying on their beds although there is less than 6 hours left before the occurrence of landfall, these patients are brought to the staging area without passing the staging area capacity and seize the nurses in the same way as explained above for the patients waited in the staging area for a vehicle.

\subsection{Influence of Traffic}

Analyzing the impacts of the decisions made by the hospital operators is one of the purposes of this research. The total evacuation time is bounded to the start time of evacuation as traffic will change over time because of the mass evacuation due to the hurricanes. Thus, the allocation of the resources is indirectly dependent on traffic because the hospital operators intend to evacuate all patients within a pre-specified time period.

During literature review, it is seen that behavioral curves for the case of an evacuation are generated as a result of FEMA/Corps Hurricane Study Program. Figure 1 displays the sigmoid curves or s-curves utilized for the determination of behavioral response. As seen from the figure, small amount of people start evacuating approximately two hours before the evacuation order. After evacuation order, there is a considerable increase in the number of evacuees leaving their houses, the peak of which is observed around $3 \mathrm{hrs}, 6 \mathrm{hrs}$, and $8 \mathrm{hrs}$ for rapid, medium, and long responses, respectively. 


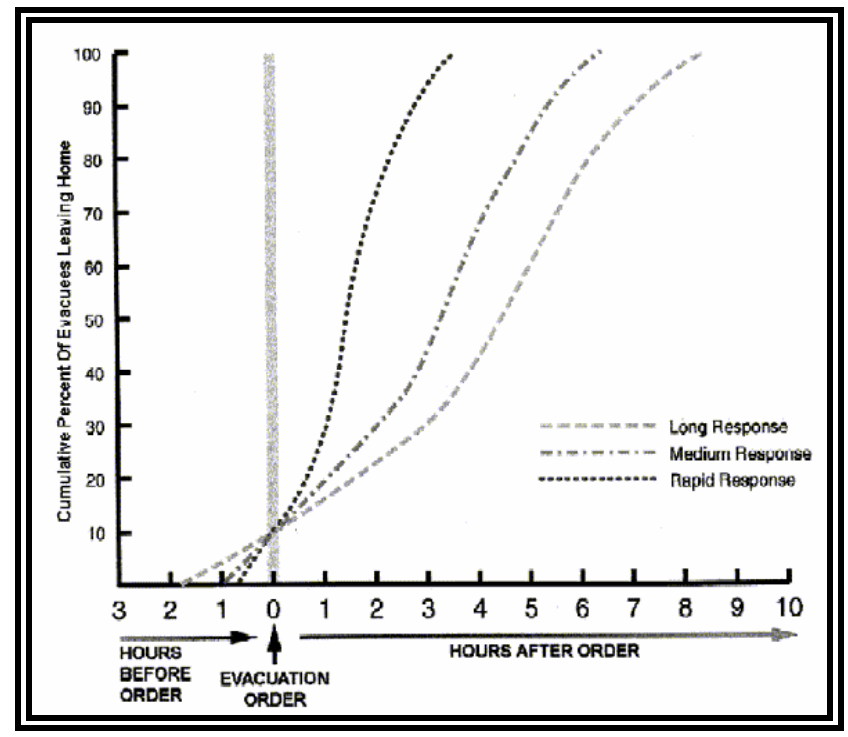

Figure 1: Behavioral response curves, S-curve

However, this figure and other articles mentioned in literature review did not provide enough information in terms of expected increase in travel times over time. Hence, all of the information obtained from these previous researches is comprehended and interpreted in order to specify traffic factor estimates based on evacuation order. The changes in traffic factor over time when traveling from evacuating region to safe neighbor regions are given in Figure 2, while Figure 3 displays this for the inverse direction.

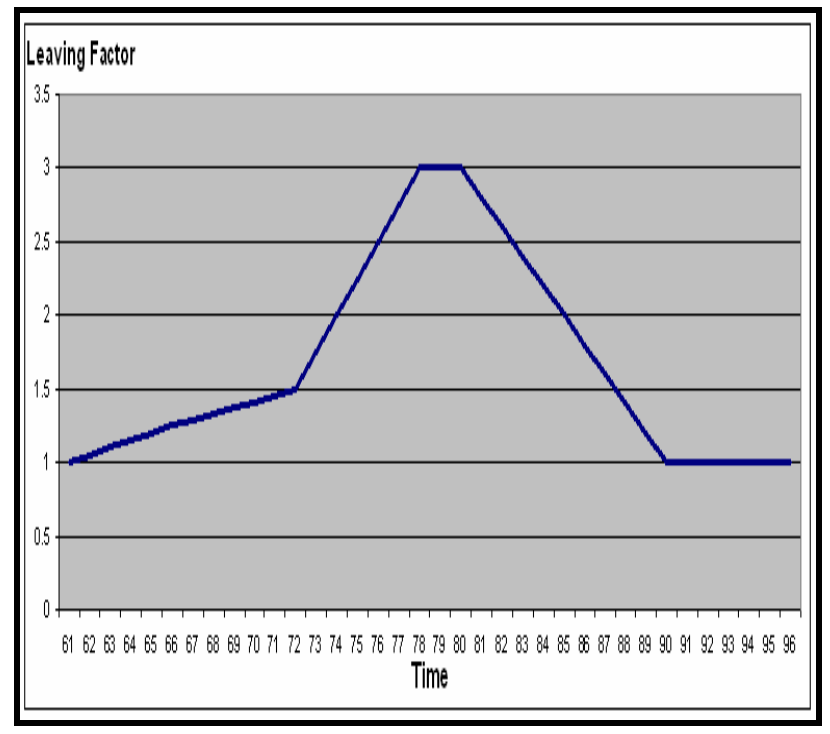

Figure 2: Leaving traffic factor versus time

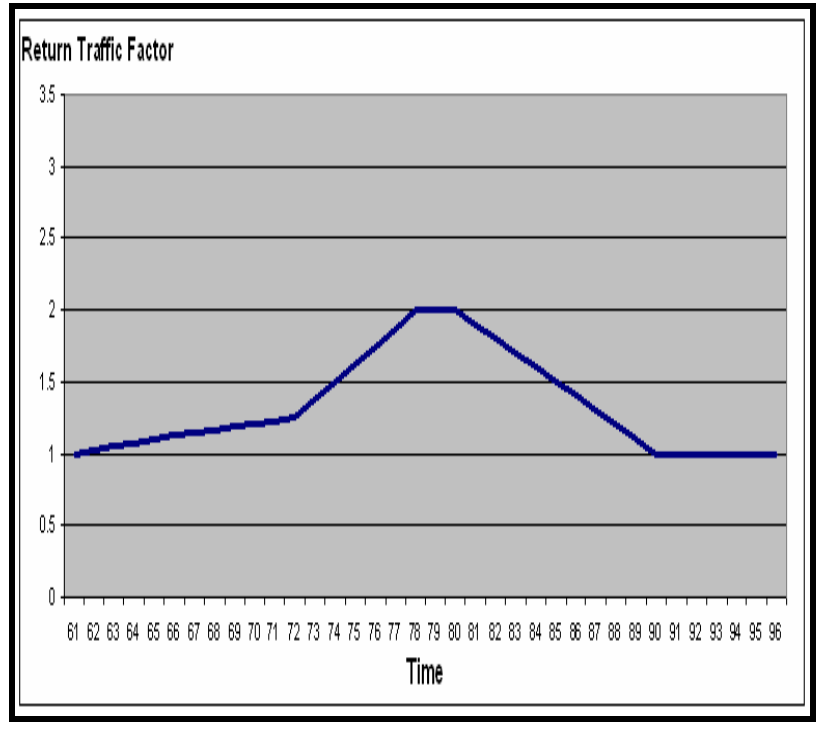

Figure 3: Return traffic factor versus time

As mentioned earlier, the landfall of a hurricane is assumed to be known 96 hours earlier than actual occurrence of the landfall. Also, evacuation order is assumed to be given 24 hours before landfall by the government. As seen from these figures, traffic increases very slightly between the time when evacuation order is given and 36 hours earlier than landfall. However, it increases very quickly as most of the peoples' intentions to move away from hazard. Traffic reaches its peak value 6 hours after governments' evacuation order and keeps constant for several periods. Afterwards, it starts to decrease very rapidly again and acts as normal 6 hours before landfall. Note that the travel times from the evacuating region to safe neighboring region will be higher than the travel times from the safe neighboring region to the evacuating region for some periods due to the fact that people tends to evacuate the dangerous region. These travel time estimates are included into the model for the travel time calculations.

\section{CONCLUSION AND FUTURE RESEARCH}

In this paper, the definition of the system is finalized with the information obtained from risk managers and officials of several hospitals. During these information sessions, some of the information they gave was specific to their hospitals. Therefore, assumptions and rules that are followed during evacuation are specified as general as possible so that this model can be applicable to all hospitals. This system is modeled with the use of a commerciallyavailable simulation software package, Arena. The model is built as flexible as possible in order that hospital operators can use this model with few input parameter changes. It is a very complex model as can be understood from the rules mentioned in earlier sections. There are so many dif- 


\section{Tayfur and Taaffe}

ferent scenarios needed to be followed for the allocation of resources, which results in a very big complicated model (e.g. there are 150 decision modules and different procedures that follow these decision modules). Although the model is finalized, some debugging problems are encountered and the authors are still working on fixing these problems because of the complexity of the model.

After fixing these problems, the effect of traffic will be analyzed for different evacuation start times. Alternative models will be created and at least one model better than the base model will be tried to be found. One of the alternative models currently considered is the model when each vehicle type is allowed to transfer only one type of patient. In this model, an ambulance can only transfer Type 1 patients, whereas van/bus can only transfer Type $2 / 3$ patients respectively. Another alternative is to have only two vehicle types: ambulances and buses. More alternatives will be modeled in order to improve the system as much as possible. The differences between alternative models will be examined for a large number of scenarios. After selecting the best alternative model, resources for base model and best alternative model will be allocated via simulationoptimization approach (OptQuest) for a large number of scenarios. As mentioned, the authors have also proposed a deterministic optimization model. When their work related to this optimization model is finished, allocations of resources found by optimization approach and simulationoptimization approach will be compared for same inputs.

\section{REFERENCES}

Chang, E. C. 2003. Traffic simulation for effective emergency evacuation. Available via http://www. ic tpaweb.org/publication/NCA/conferean 03/Proceeding/074.pdf [accessed June 21, 2005].

Chen, X. 2003. Agent-based simulation of evacuation strategies under different road network structures. Available via <http://www. ucgis.org/summe r03/studentpapers/xuweichen.pdf> [accessed September 27, 2006].

Department of Health and Environmental Control (DHEC). 2004. Emergency order - evacuation plans. state of south carolina. August 30, 2004. Available via <http://www.scdhec.net/hr/pdfs/licen /licgen/hleo.pdf> [accessed December 14, 2006].

de Silva, F.N., R.W. Eglese, and M. Pidd. 2003. Evacuation planning and spatial decision making: designing effective spatial decision support systems through integration of technologies. In Decision making support systems: achievements, trends and challenges for. Idea Group Publishing, 358-373.

FEMA/Corps Hurricane study program, 1986-2006. transportation/clearance time data. Available via
<http://chps.sam.usace.army.mil/USHE Sdata/Assessments/opal/chapter_5.htm $>$

Frantzich, H. 1997. Fire safety risk analysis of a healthcare facility. department of fire safety engineering, Lund University, October 11, 1997. Available via <http://www.brand.lth.se/bibl/3085.p df $>$ [accessed January 30, 2006].

Hobeika, A.G. and B. Jamei. 1985. MASSVAC: A model for calculating evacuation times under natural disaster. Emergency Planning, Simulation Series 15:23-28.

McGlown, K. J. 1999. Determinants of the evacuation of health care facilities. Ph.D. Dissertation, University of Alabama at Birmingham.

Pidd, M., F.N. de Silva, and R.W. Eglese. 1996. A simulation model for emergency evacuation. European Journal of Operational Research 90(3):413-419.

Radwan, E., M. Mollaghasemi, S. Mitchell, and G. Yildirim. 2005. Framework for modeling emergency evacuation. Final project report submitted to Florida Department of Transportation, April 2005. Available via <http://www.catss.ucf.edu/projects/d ocuments/reports/htm/projectFR_58.ht $m>$ [accessed December 10, 2006].

Quarantelli, E.L. 1980. Evacuation behavior and problems: findings and implications from the research literature. Disaster Research Center. Ohio State University, Columbus, Ohio.

Sheffi, Y., H. Mahmassani, and W.B. Powell. 1982. A transportation network evacuation model. Transportation Research Part A 16(3):209-218.

Sorensen, J.H. and D. Mileti. 1987. decision-making uncertainties in emergency warning system organization. International Journal of Mass Emergencies and Disasters 5(1):33-62.

Sorensen, J.H. 1991. When shall we leave? factors affecting the timing of evacuation departures. International Journal of Mass Emergencies and Disasters 9(2):153165.

Taaffe, K., R. Kohl, and D.L. Kimbler. 2005. Hospital evacuation: issues and complexities. In Proceedings of the 2005 Winter Simulation Conference, ed. M.E. Kuhl, N.M. Steiger, F.B. Armstrong, and J.A. Joines, 943-950.

Taaffe, K. and E.Tayfur. 2006. Evaluating the robustness of hospital evacuation plans. In Proceedings of the 2006 IIE Research Conference, Paper No: 1418, Orlando, FL.

Taaffe, K., M. Johnson, and D. Steinmann. 2006. Improving hospital evacuation using simulation. In Proceedings of the 2006 Winter Simulation Conference, eds. L.F. Perrone, F.P. Wieland, J. Liu, B.G. Lawson, D.M. Nicol, and R.M. Fujimoto, 509-515. 
Tanaka, K., T. Nagatani, and H. Hanaura. 2006. Traffic congestion and dispersion in hurricane evacuation. Physica A 2006.

Tayfur, E. and K. Taaffe. 2007. Allocation of resources during hospital evacuations: a simulation approach. In Proceedings of the 2007 IIE Research Conference, Nashville, TN.

Tufekci, S. 1995. An integrated emergency management decision support system for hurricane emergencies. Safety Science 20(1):39-48.

U.S. Government Accountability Office (GAO). 2006. GAO-06-443R: preliminary observations on the evacuation of hospitals and nursing homes due to hurricanes. february 16, 2006. Available via <http: //www.gao.gov/new.items/d06443r.pdf> [accessed December 10, 2006].

Vogt, B.M. 1990. Evacuation of institutionalized and specialized populations. Oak Ridge National Laboratory, Oak Ridge, TN.

Vogt, B.M. 1991. Issues in nursing home evacuations. International Journal of Mass Emergencies and Disasters 9(2):247-265.

\section{AUTHOR BIOGRAPHIES}

KEVIN TAAFFE is an assistant professor in the Department of Industrial Engineering at Clemson University. His primary research interests include transportation and logistics systems analysis as well as production, inventory, and demand management. He is a Senior Member of IIE, as well as a member of INFORMS, Transportation Research Board, and Decision Sciences Institute. His email address is <taaffedclemson.edu> and his web address is <http://people.clemson.edu/ taaffe>.

ESENGUL TAYFUR is a Ph.D student in the Department of Industrial Engineering at Clemson University. Her email address is <etayfur@clemson.edu>. 